\title{
Metabolism of $\boldsymbol{m}$-tert.-Butylphenyl $\boldsymbol{N}$-Methylcarbamate in Insects and Mice
}

\author{
By P. G. C. DOUCH AND J. N. SMITH \\ Department of Biochemistry, Victoria University of Wellington, \\ P.O. Box 196, Wellington, New Zealand
}

(Received 17 May 1971)

\begin{abstract}
The metabolism of $m$-tert.-butylphenyl $N$-methylcarbamate was studied in mice and five species of insects. Both the tert.-butyl group and the $N$-methyl group were hydroxylated. The major phenolic metabolite was $m$-( $\beta$-hydroxy-tert.-butyl)phenol, which was identified by mass spectroscopy. Significant amounts of dihydroxy compounds were formed at a constant rate from the start of the enzymic oxidation process. The considerable species variation in the yields of the different types of oxidation products suggests that $N$-demethylation and oxidation of the tert.-butyl groups were catalysed by different enzymes. A microsomal NADPH-dependent enzyme also catalysed the splitting of the ester link in the insecticide.
\end{abstract}

Carbamate insecticides have aroused interest because of the frequency with which selective toxicity is exhibited. One important reason for this is the rapid degradation of these compounds in the more resistant species (Winteringham, 1969), but the interpretation of toxicity results in terms of species differences in metabolism has been hampered by a lack of adequate quantitative information about the nature and rates of formation of the various metabolites formed by different insects and mammals.

Oxidative routes of metabolism are of major importance in the case of the carbamate group of insecticides, and their toxicity may be greatly increased by the use of synergists that act by preventing their oxidation by the microsomal fraction (Metcalf \& Fukuto, 1965; Metcalf et al. 1966; Casida, 1969, 1970), but whether these synergists influence a single enzyme or whether several microsomal hydroxylases are concerned in carbamate detoxication is not known.

It was thought that an assessment of the different types of hydroxylated metabolites of a single carbamate in several species might throw some light on this. The choice of $m$-tert.-butylphenyl $N$-methylcarbamate for study was made because it had relatively low toxicity and because oxidative detoxication could be presumed to be important, since in enzyme assays this insecticide is a highly effective inhibitor of acetylcholine esterase (Moorefield, 1960; Metcalf \& Fukuto, 1965; Metcalf, Fukuto \& Winton, 1962).

A further reason for the study of this compound was the great difference in its effective toxicity in flies and mice (Fraser, Greenwood, Harrison \& Wells, 1967), since we have suggested that the oxidation of a selectophoric alkyl group in an insecticide molecule might account for the relatively low toxicity of some carbamates in mammals as compared with insects (Hook \& Smith, 1967).

\section{MATERIALS AND METHODS}

Compounds. o-tert.-Butylphenyl $N$-methylcarbamate, m.p. $95^{\circ} \mathrm{C}, m$-tert.-butylphenyl $N$-methylcarbamate, m.p. $110^{\circ} \mathrm{C}, p$-tert.-butylphenyl $N$-methylcarbamate, m.p. $143^{\circ} \mathrm{C}, \quad 3,5$-di-tert.-butylphenyl $N$-methylcarbamate, m.p. $102^{\circ} \mathrm{C}$, and $o$-isopropoxyphenyl $N$-methylcarbamate, m.p. $91^{\circ} \mathrm{C}$, were prepared from the phenols and methyl isocyanate in the presence of triethylamine (Kolbezen, Metcalf \& Fukuto, 1954). m-tert.-Butylphenyl carbamate was prepared by the method of Raiford \& Inman (1934) and had m.p. $168^{\circ} \mathrm{C}$ (Found: $\mathrm{C}, 68.2 ; \mathrm{H}, 7.9 ; \mathrm{N}, 7.2$. $\mathrm{C}_{11} \mathrm{H}_{17} \mathrm{NO}_{2}$ requires $\mathrm{C}, 68.4 ; \mathrm{H}, 7.8 ; \mathrm{N}, 7.3 \%$ ).

m-tert.-Butylphenol was tritiated by the method of Hilton \& O'Brien (1964) and purified by t.l.c. as described below. It was converted into the $N$-methylcarbamate by treatment with methyl isocyanate, and the $\left[{ }^{3} \mathrm{H}\right] m$-tert.butylphenyl $N$-methylcarbamate was purified by t.l.c. Stock solutions of this material were diluted with unlabelled material to give a specific radioactivity of $0.9 \mathrm{Ci} /$ mol for experimental use. 3,5-di-tert.-Butylphenyl $N$. methylcarbamate (Butacarb) was similarly tritiated and purified $(0.1 \mathrm{Ci} / \mathrm{mol})$. $\left[{ }^{14} \mathrm{C}\right]$ o-Isopropoxy-[1,3-14 $\left.\mathrm{C}\right]$ phenyl $N$-methylcarbamate $(1.0 \mathrm{Ci} / \mathrm{mol})$ was provided by the Vector Control Division, World Health Organization, Geneva, Switzerland.

Experimental animals. Houseflies (Musca domestica) and blowflies (Lucilia sericata) were reared and maintained as described previously (Jordan \& Smith, 1970) and were used as 3-day-old adults in most experiments. Bioch. 1971, 125 
Seven strains of houseflies were used in this work; six of these had been selected from an original polymorphic strain. These were a strain with a low resistance to DDT [1,1,1-trichloro-2,2-di-( $p$-chlorophenyl)ethane $](V)$, strains with high DDT resistance associated with a dehydrochlorination mechanism (VD and A), strains that were under pressure with carbamates and lindane respectively but had not yet shown increased resistance to these insecticides (VC and VL), a strain with white eyes but otherwise identical with the $V$ strain $(Y)$, and a wild strain collected in Wellington with a low DDT resistance of about the same degree as the V strain (M). Grass grubs (Costelytra zealandica) were collected by the New Zealand Department of Scientific and Industrial Research Entomology Division and stored at $5^{\circ} \mathrm{C}$ in moist earth before use. Bees (workers from an Apis mellifera colony) were collected from the front of the hive in a net and used immediately. Meal worms (Tenebrio sp.) were reared in a dry flour-yeast medium; larvae, pupae and adults were used.

Eight-week-old male mice were used for work with vertebrates.

Preparation of enzymes. Mouse liver was homogenized at $0^{\circ} \mathrm{C}$ in a Teflon-and-glass Potter-Elvehjem homogenizer in $6 \mathrm{vol}$. of $0.1 \mathrm{~m}-\mathrm{KH}_{2} \mathrm{PO}_{4}-\mathrm{Na}_{2} \mathrm{HPO}_{4}$ buffer, $\mathrm{pH}$ 7.4. The mixture was centrifuged at $10000 \mathrm{~g}$ for $10 \mathrm{~min}$ and the supernatant used as enzyme for most experiments. Mouse microsomal fraction was prepared by centrifuging the $10000 \mathrm{~g}$ supernatant at $100000 \mathrm{~g}$ in an MSE Superspeed 50 centrifuge and 4210 angle rotor for 1h. All mouse enzyme incubations were at $37^{\circ} \mathrm{C}$ and contained enzyme equivalent to $1 \mathrm{~g}$ of liver in $10 \mathrm{ml}$ of the 0.1 M-phosphate buffer, pH7.4. In incubations with $10000 \mathrm{~g}$ supernatant in a shaking water bath in air, the cofactors added were $10 \mathrm{~mm}$-nicotinamide, $15 \mathrm{~mm}-\mathrm{MgCl}_{2}$, $0.1 \mathrm{~mm}-\mathrm{NAD}^{+}, \quad 0.1 \mathrm{~mm}-\mathrm{NADP}^{+}$and $4 \mathrm{~mm}-$ glucose 6 phosphate.

Enzymes from houseflies or blowflies were prepared from fly abdomens by the procedure described by Jordan $\&$ Smith (1970). Incubation mixtures contained the same cofactors as for the mouse enzyme except for nicotinamide and $\mathrm{MgCl}_{2}$, and a concentration of fly enzyme equivalent to 2 abdomens/ml was used (ef. Jordan \& Smith, 1970). Incubations were at $30^{\circ} \mathrm{C}$ and were terminated, usually after $30 \mathrm{~min}$, by addition of an equal volume of ether to extract substrates and metabolites. Substrate concentrations in all experiments were $1 \mathrm{~mm}$ and controls were used that contained no substrate.

Dosing of insects. Non-radioactive compounds were given topically in acetone solution by using calibrated $1 \mu l$ capillary tubes. In experiments with radioactive compounds insects were dosed topically with $0.13 \mu \mathrm{l}$ of acetone solution containing $0.9 \mu \mathrm{g}$ of $\left[{ }^{3} \mathrm{H}\right] m$-tert.-butylphenyl $N$-methylcarbamate from a calibrated capillary tube and the adults were kept in groups of 20-50 in $20 \mathrm{~cm} \times$ $4 \mathrm{~cm}$ test tubes closed with wire mesh. Larval stages were kept in small Petri dishes. In most experiments the dose contained $8850 \pm 600$ c.p.m./insect.

Measurement of ${ }^{3} \mathrm{H}$ radioactivity. Radioactivity was measured in a Packard series 4000 scintillation spectrometer. Materials soluble in organic solvents were counted at $25 \%$ efficiency in a sointillation mixture containing $5 \mathrm{~g}$ of 2,5 -diphenyloxazole and $0.3 \mathrm{~g}$ of 1,4 -bis-(5-p-tolyloxazol-2-yl)benzene/l of toluene. Aqueous samples (1 ml) were counted at $20 \%$ efficiency in similar solutions in which one-third of the toluene had been replaced by Triton X-100 (Rohm and Haas Co., Philadelphia, Pa., U.S.A.) (Turner, 1968). Efficiencies in counting of radioactivities of solutions were assessed by reference to a quench correlation curve by using the automatic external standardization facility. Radioactivities of samples of toluene-soluble metabolites on sections of chromatography paper $(2 \mathrm{~cm} \times 1 \mathrm{~cm})$ were counted in $2 \mathrm{ml}$ of scintillation fluid. No difference in the c.p.m. was found between samples whose radioactivities were counted in this way and duplicate samples whose radioactivities were counted after chromatographic elution and assay in full vials of scintillation fluid. Radioactivities of solutions or suspensions ( $1 \mathrm{ml}$ ) containing protein were counted after heating at $100^{\circ} \mathrm{C}$ with $1 \mathrm{ml}$ of formic acid. These solutions were neutralized by $2 \mathrm{M}-\mathrm{NaOH}$ and their radioactivities counted in the Triton X-100-toluene scintillant.

Extraction of metabolites. Enzyme incubations, usually $10 \mathrm{ml}$ total volume, were extracted after $30 \mathrm{~min}$ four times with equal volumes of ether; this, in experiments with radioactive compounds, was sufficient to remove all radioactivity from the aqueous layer. The ether was dried with anhydrous $\mathrm{Na}_{2} \mathrm{SO}_{4}$, evaporated in vacuo at $30^{\circ} \mathrm{C}$ and the extract dissolved in $0.2 \mathrm{ml}$ of dioxan for further examination.

Whole insects were immobilized with $\mathrm{CO}_{2}$ and then ground with an equal weight of acid-washed sand in a glass mortar with $5 \mathrm{ml}$ of ether. Four successive portions of ether were used to rinse out the sand and ether; this, in experiments with radioactive compounds, was sufficient to remove all radioactivity from the aqueous layer. The ether was dried with $\mathrm{Na}_{2} \mathrm{SO}_{4}$, evaporated in vacuo at $30^{\circ} \mathrm{C}$ and the extract dissolved in $0.2 \mathrm{ml}$ of dioxan for further examination.

Containers that had held live insects were rinsed out with $20 \mathrm{ml}$ of acetono-ethanol-water (1:1:2, by vol.) and the rinsings added to the extract of ground insects. The radioactivity of a pellet of centrifuged tissue and sand remaining after centrifuging these extracts was also counted, but this was negligible in experiments with radioactive compounds. Measured portions of the aqueous fraction from this extraction procedure were hydrolysed enzymically to decompose any conjugated metabolites present. An acetone-dried powdered preparation of Haliotis australis viscera $(100 \mathrm{mg})$ was used as enzyme and the aqueous layers were incubated at $\mathrm{pH} 5.5$ for $12 \mathrm{~h}$ before extraction of metabolites as described above. This enzyme preparation contained $\beta$-glucosidase, $\beta$-glucuronidase, arylsulphatase and phosphatase, but did not hydrolyse the carbamate ester linkage in control experiments with ${ }^{3} \mathrm{H}$-labelled $m$-tert.-butylphenyl $N$ methylcarbamate. Total recovery of radioactive material from live insects in these experiments was in the range 98-102\% of the applied dose.

Chromatography and ionophoresis. Some t.l.c. was carried out with $0.25 \mathrm{~mm}$-thick layers of silica gel G (E. Merck A.-G., Darmstadt, Germany) activated at $120^{\circ} \mathrm{C}$ and plates were usually developed for $15 \mathrm{~cm}$ in ether-iso-octane $(4: 1, \mathrm{v} / \mathrm{v})$. Whatman silica-gel-loaded paper no. SG81 was found more convenient, as it required no activation and samples were developed by descending chromatography for $45 \mathrm{~cm}$ in the same solvent. Ionophoresis was carried out in the Shandon high-voltage 
apparatus as previously described (Jordan, McNaught \& Smith, 1970) (Table 1).

Colour reactions. Chromotropic acid $(0.2 \%$ in $6 \mathrm{M}$ $\mathrm{H}_{2} \mathrm{SO}_{4}$ ) at $100^{\circ} \mathrm{C}$ gave purple colours with $N$-hydroxymethyl derivatives (Metcalf et al. 1968). Phenolic metabolites were detected with diazotized $p$-nitroaniline or 2,6-dichloroquinonechloroimide (Hook \& Smith, 1967). Carbamate esters and phenols were detected by first spraying with $1 \mathrm{~m}-\mathrm{NaOH}$ in ethanol-water $(1: 1, \mathrm{v} / \mathrm{v})$ followed by the phenol-detecting reagents. Phenyl oarbamates and phenyl $N$-methylcarbamates were detected by red-purple colours given in their reaction with $2 \%(w / v)$ ninhydrin in acetone containing collidine $(0.1 \%)$ at $100^{\circ} \mathrm{C}$ (Gemrich, 1967). With $p$-dimethylaminobenzaldehyde $(20 \%, w / v$, in acetic acid) phenyl carbamates gave yellow colours in the cold, and phenyl $N$ methylcarbamates gave similar colours on heating to $100^{\circ} \mathrm{C}$ (Feigl, 1956, p. 273). p-Dimethylaminocinnamaldehyde gave red to orange colours under similar conditions. 1,3-Dihydroxyphenols gave coloured and fluorescent products when heated for $30 \mathrm{~min}$ at $100^{\circ} \mathrm{C}$ after spraying with $1 \%(\mathrm{w} / \mathrm{v}) 0$-phthalaldehyde in conc. $\mathrm{H}_{2} \mathrm{SO}_{4}$ or with $1 \%(\mathrm{w} / \mathrm{v}) \mathrm{o}$-sulphobenzoic anhydride in conc. $\mathrm{H}_{2} \mathrm{SO}_{4}$ (Feigl, 1956, p. 382). Colours were intensified by spraying with $10 \mathrm{~m}-\mathrm{NaOH} ; 1,3$-dihydroxyphenols also gave yellow colours when they were sprayed with $5 \%$ $(\mathrm{w} / \mathrm{v})$ fructose in $6 \mathrm{M}-\mathrm{HCl}$ and heated to $100^{\circ} \mathrm{C}$. Aldehydes gave yellow colours when sprayed with di-o-anisidine in acetic acid and also dark spots with ammoniacal $\mathrm{AgNO}_{3}$.

Gas-liquid chromatography. A Perkin-Elmer 801 gas chromatograph was used with a flame ionization detector. Columns $(0.4 \mathrm{~cm} \times 40 \mathrm{~cm}$ long) were packed with $5 \%$ (w/w) Carbowax 600 on 80 -mesh Celite that had been treated with $2 \%(w / v)$ phosphoric acid (Kolloff, Breuklander \& Barkley, 1963). Retention times at 70,85 and $125^{\circ} \mathrm{C}$ with $\mathrm{N}_{2}$ as carrier at $120 \mathrm{ml} / \mathrm{min}$ column flow are shown in Table 1. Comparisons of retention times were made with injections of both separate and mixed compounds.

\section{RESULTS}

Enzymic oxidation of m-tert.-butylphenyl N-methylcarbamate

In mouse liver preparations. Incubations were made as described above with enzyme from $1 \mathrm{~g}$ of liver in a total volume of $10 \mathrm{ml}$. After $0.5 \mathrm{~h}$ the substrate and products were extracted with ether as described above and samples of the extract were separated in the t.l.c. system or on Whatman no. SG81 paper. Eight coloured spots were obtained, and these were identified as the compounds listed in Table 2 by use of the colour reactions described below. Two, metabolites $e$ and $h$, were phenolic, since they gave colours immediately with diazotized $p$-nitroaniline; the rest were phenol esters which gave this reaction after preliminary treatment with 1 M-sodium hydroxide. Two spots, metabolites $a$ and $d$, gave the purple colour with chromotropic acid characteristic of $N$-hydroxymethyl derivatives. Two, metabolites $b$ and $f$, gave yellow colours with $p$-dimethylaminobenzaldehyde and acetic acid in

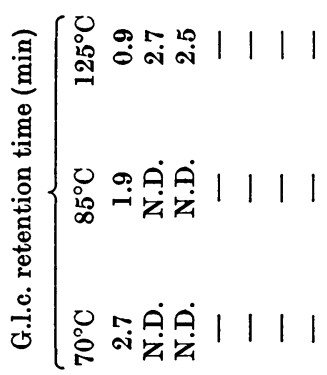

:

要

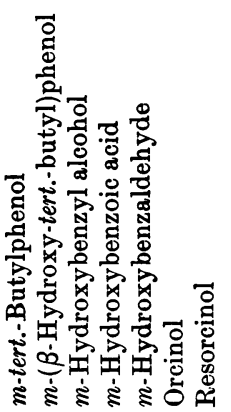




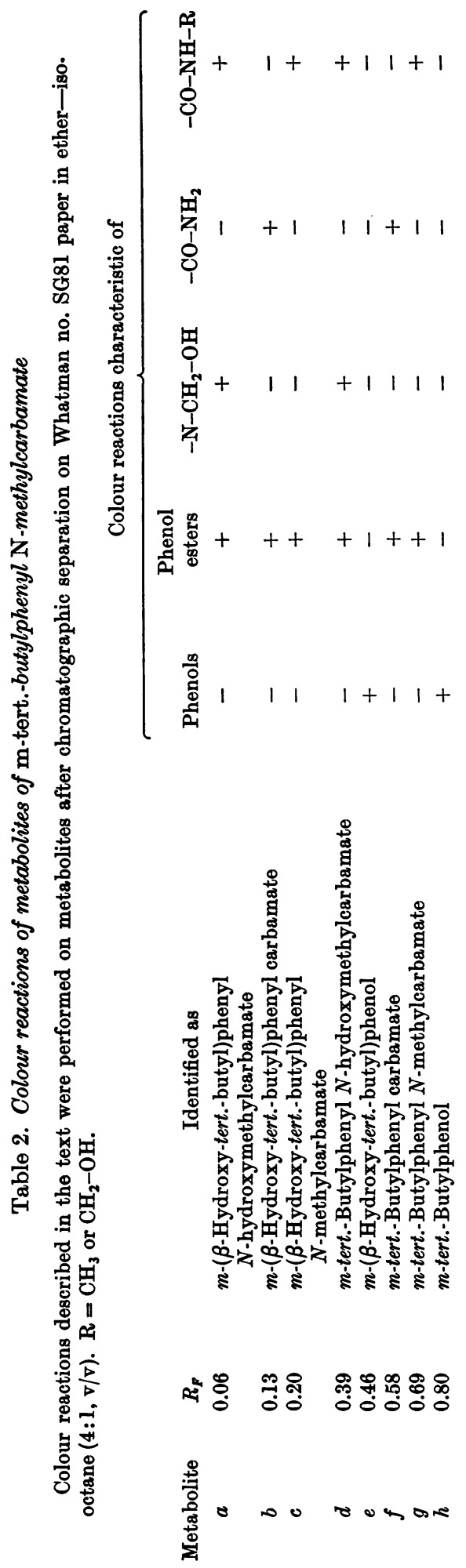

the cold, which is given by esters of carbamic acid, and the metabolites $a, c, d$ and $g$ gave this reaction only on heating and were presumed to be $N$-substituted carbamates. Spots were eluted chromatographically from Whatman no. SG81 paper with ether, and the concentrated eluates were hydrolysed by warming with a drop of 1 M-sodium hydroxide. After acidification and transfer to a small volume of ether the hydrolysis products were chromatographed on Whatman no. SG81 paper or the g.l.c. system and separated by ionophoresis in each of the systems given in Table 1. No carboxylic acids could be detected by their ionophoretic behaviour. Metabolites $a, b$ and $c$ yielded on hydrolysis a compound identical with the phenolic metabolite $e$ on chromatography and ionophoresis and by colour reactions. Metabolites $d, f$ and $g$ yielded a hydrolysis product with behaviour identical with that of $m$-tert.-butylphenol (metabolite $h$ ). Only one phenolic product was found after hydrolysis of each of the eight spots, and no diphenols were detected with ammoniacal silver nitrate or colour reagents for $m$-dihydroxybenzenes. No colour reactions for aldehydes were obtained.

Samples of the two phenolic hydrolysis products from a number of separate experiments were pooled and chromatographed in ether-iso-octane on the t.l.c. system, and the appropriate zones $\left(R_{F} 0.5\right.$ and 0.8 ) were eluted and evaporated to yield approx. $0.5 \mathrm{mg}$ of residue in each case. These were heated separately on a boiling-water bath in $0.5 \mathrm{ml}$ of aq. $5 \%(\mathrm{w} / \mathrm{v})$ phosphoric acid and $0.5 \mathrm{ml}$ of aq. $5 \%(\mathrm{w} / \mathrm{v})$ potassium permanganate for $15 \mathrm{~min}$. Each solution was decolorized with solid sodium metabisulphite and $2.5 \mathrm{ml}$ of formic acid, and then extracted with ether. After being dried with sodium sulphate and evaporation, portions of the two ether solutions were examined in the separation systems and compared with the reference compounds listed in Table 1. Two compounds giving the colour reactions of phenols were present in each case, one of which behaved identically with the unchanged hydrolysis product (metabolite $e$ or $h$ ) and the other with $m$ hydroxybenzoic acid. Products with $R_{F}$ values identical with that of $m$-hydroxybenzoic acid in system $B$ (Table 1) were also obtained by similar oxidations of reference m-tert.-butylphenol, but orcinol yielded a different product, presumably $\alpha$ resorcylic acid, having $R_{F} 0.3$ in solvent system $B$.

Samples of metabolite $e$ were obtained by pooling 50 mouse liver incubations, hydrolysing the ether extracts with sodium hydroxide as above and separating the liberated phenolic material in solvent system $A$. The phenolic metabolite $e, R_{F} 0.5$, was eluted with ether and purified by micro-distillation at $150^{\circ} \mathrm{C}$ and $20 \mathrm{mmHg}$. The colourless oil was dissolved in ether, and mass-spectral measurements were made by Professor R. Hodges with an A.E.I. 
MS902b mass spectrometer. Major $m / e$ peaks were obtained at 166, 135, 107, 95 and 77 ; the empirical formula for each of these peaks was determined by precise mass measurements and the pathways were shown by metastable peaks. Mass-spectral data were consistent with the identification of metabolite $e$ as $m$-( $\beta$-hydroxy-tert.-butyl)phenol and showed that breakdown pathways were probably as indicated in Scheme 1.

In housefly and blowfly enzyme preparations. Similar incubations were carried out in enzyme prepared from housefly and blowfly abdomens with $m$-tert.-butylphenyl $N$-methylcarbamate as substrate. Each incubation mixture contained the equivalent of 100 flies in a total volume of $50 \mathrm{ml}$. Extraction and chromatography were carried out as above and eight spots were detected by t.l.c. with $R_{F}$ values identical with those obtained in parallel experiments with mouse enzymes. The metabolites were identified as described above for the mouse metabolites by their colour reactions and by ionophoresis, chromatography and g.l.c. of hydrolysis products in the systems given in Table 1. Fly metabolites were identical with those from the mouse experiments, and no other metabolites were found.

Quantitative assays. Incubations were carried out with mouse, housefly and blowfly preparations with $0.1 \mu \mathrm{Ci}$ of $\left[{ }^{3} \mathrm{H}\right] m$-tert. - butylphenyl $N$-methyl carbamate. Incubation mixtures were extracted with ether after $0.5 \mathrm{~h}$ and chromatographed on t.l.c. systems or on Whatman no. SG81 paper as described above. Zones corresponding with the eight chromatographic spots were eluted and their radioactivities counted in the scintillation spectrometer as described above. Results of these experiments are listed in Table 3. Similar experiments with mouse enzyme and housefly enzyme were performed at

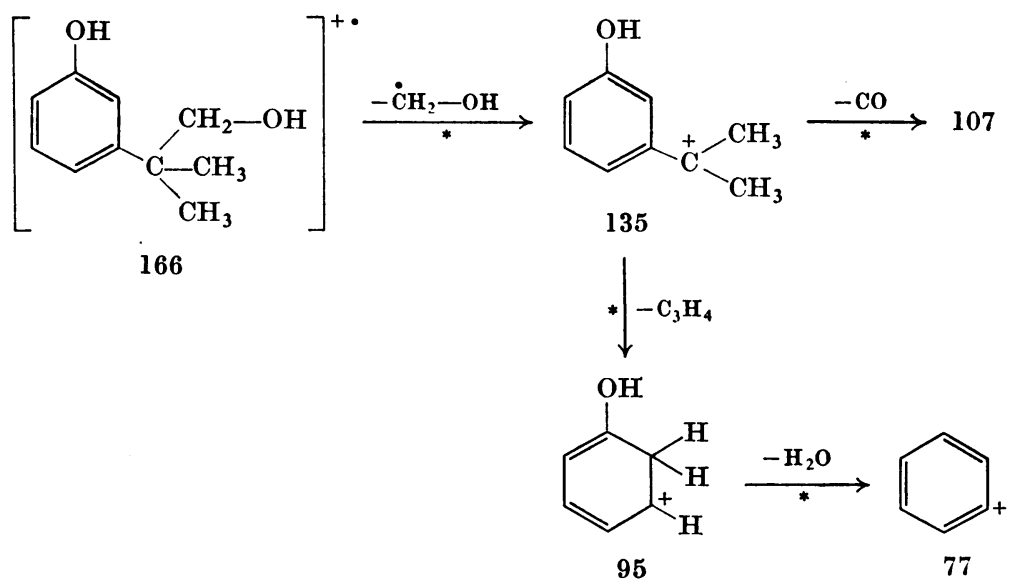

Scheme 1. Probable breakdown pathway of $m$-( $\beta$-hydroxy-tert.-butyl)phenol (metabolite $e$ ) during mass spectrometry.

Table 3. Enzymic metabolism of $\left[{ }^{3} \mathrm{H}\right] \mathrm{m}$-tert.-butylphenyl $\mathrm{N}$-methylcarbamate

The substrate ( $1 \mathrm{mM}$ ) was incubated at $37^{\circ} \mathrm{C}$ in $10 \mathrm{ml}$ of $0.1 \mathrm{~m}$-phosphate buffer, $\mathrm{pH} \mathrm{7.4,} \mathrm{containing} 0.1 \mathrm{~mm}$ $\mathrm{NADP}^{+}, 0.1 \mathrm{~mm}-\mathrm{NAD}^{+}, 4 \mathrm{~mm}$-glucose 6-phosphate and the $10000 \mathrm{~g}$ supernatant of a homogenate of $1.0 \mathrm{~g}$ of mouse liver in $0.1 \mathrm{M}$-phosphate buffer. Housefly and blowfly experiments were similar except that the enzyme preparation was an homogenate of $20 \mathrm{fly}$ abdomens in $0.1 \mathrm{~m}$-phosphate buffer, pH 7.4. Metabolites were those identified in Table 2. Results are listed as mean values with ranges in parentheses and numbers of experiments as a superscript.

\begin{tabular}{cccccc}
$\begin{array}{c}\text { Metabolite } \\
\text { Source of enzyme }\end{array}$ & $\ldots$ & \multicolumn{4}{c}{ Rate of formation ( $\mu$ mol/h per $\mathrm{g}$ of fly or liver) } \\
\cline { 2 - 6 }$a$ & & $0.05(0.05)^{4}$ & $0.14(0.10-0.32)^{12}$ & $0.57(0.55-0.60)^{2}$ & $0.11(0.02-0.17)^{10}$ \\
$b$ & & $0.03(0.03)^{4}$ & $0.14(0.08-0.29)^{12}$ & $-0.22(0.22)^{2}$ & $0.04(0.01-0.06)^{10}$ \\
$c$ & & $0.17(0.17)^{4}$ & $0.18(0.10-0.58)^{12}$ & $0.34(0.32-0.36)^{2}$ & $0.70(0.33-0.82)^{10}$ \\
$d$ & & $0.08(0.07-0.09)^{4}$ & $0.25(0.13-0.67)^{12}$ & $0.35(0.34-0.37)^{2}$ & $1.06(0.24-1.28)^{10}$ \\
$e$ & $0.02(0.01-0.02)^{4}$ & $0.07(0.00-0.19)^{12}$ & $0.15(0.10-0.19)^{2}$ & $0.04(0.01-0.06)^{10}$ \\
$f$ & & $0.17(0.17)^{4}$ & $0.38(0.15-0.65)^{12}$ & $0.17(0.16-0.19)^{2}$ & $0.96(0.45-1.13)^{10}$ \\
$h$ & & $0.11(0.09-0.13)^{4}$ & $0.12(0.00-0.36)^{8}$ & $0.83(0.80-0.86)^{2}$ & $0.86(0.22-1.36)^{10}$
\end{tabular}


pH values between 6 and 9 , and the amount of each metabolite produced at the different values was plotted as pH-activity curves. For each metabolite the maximum rate of production occurred between pH 7 and 7.5. Similar experiments were made with mouse enzyme and housefly enzyme at pH 7.4 in which portions of the incubation mixture were withdrawn and analysed chromatographically for the seven metabolites at $10 \mathrm{~min}$ intervals. Rates of formation of each of the metabolites were constant up to 0.5 h (Fig. 1).

Enzymic oxidation of m-tert.-butylphenol and m-tert.-butylphenyl carbamate

Mouse liver incubations were performed, as described above, in which $m$-tert.-butylphenol was used as a substrate. Extraction of the incubation mixture after $0.5 \mathrm{~h}$ followed by chromatography in ether-iso-octane on Whatman no. SG81 paper showed the presence of only two products. These were eluted and examined ionophoretically in each of the chromatographic systems given in Table 1 and shown to have properties identical with those of $m$-tert.-butylphenol and $m$-( $\beta$-hydroxy-tert.-butyl)phenol (metabolite $e$ from mice). Similar experiments with $m$-tert.-butylphenyl carbamate yielded chromatograms with four spots. These had the same $R_{F}$ values and colour reactions as metabolites $b, e, f$ and $h$ found in the metabolism of $m$-tert.butylphenyl $N$-methylcarbamate in mouse liver. On elution with ether and hydrolysis in $1 \mathrm{M}$-sodium hydroxide each of the four metabolites gave only one phenolic hydrolysis product, namely $m$-tert.-

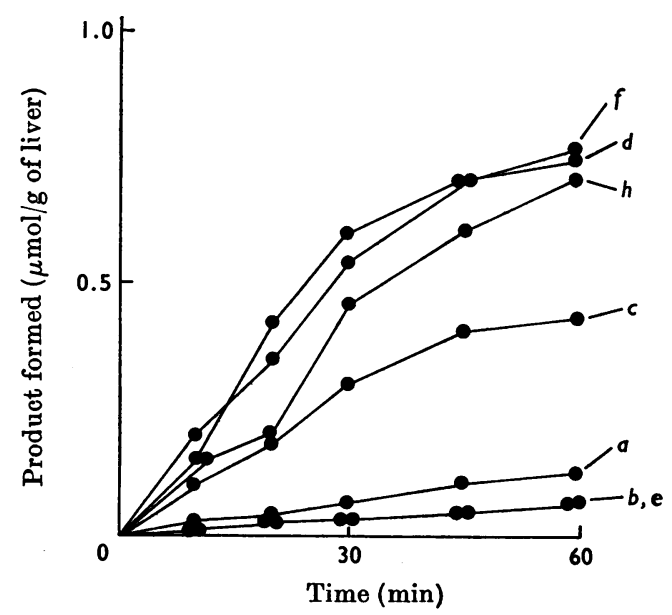

Fig. 1. Formation of metabolites of $\left[{ }^{3} \mathrm{H}\right] m$-tert.-butylphenyl $N$-methylcarbamate in mouse liver enzyme preparations. Incubation conditions were the same as in Table 3. Portions were withdrawn, extracted and analysed for metabolites by t.l.c. as described in the text. Metabolites $a-h$ are those identified in Table 2 . butylphenol from metabolites $f$ and $h$ and $m$ - $(\beta$ hydroxy-tert. -butyl)phenol from metabolites $b$ and $e$.

\section{Enzymic oxidation of o- and p-tert.-butylphenyl $\mathrm{N}$-methylcarbamate}

Incubations were carried out with mouse enzyme and extractions made as described above with $p$-tert.-butylphenyl $N$-methylcarbamate, and the extracts were chromatographed in the t.l.c. system as described above. Eight spots were again detected on these chromatograms with the colour reagents used, and these spots were not significantly different in $R_{F}$ values from the corresponding spots found in experiments with the meta isomer. Each of the eight spots was eluted with ether and hydrolysed with sodium hydroxide, and the liberated phenol was subjected to ionophoresis at the $\mathrm{pH}$ values given in Table 1. These hydrolysed solutions from the para isomer contained phenolic material that could not be distinguished, by the methods used, from the corresponding phenols liberated by hydrolysis of the analogous spots from chromatograms of the m-tert.-butylphenyl $N$-methylcarbamate.

Similar incubation mixtures carried out with the o-tert.-butylphenyl $N$-methylcarbamate were extracted and after chromatography in the t.l.c. system also gave rise to eight spots with $R_{F}$ values not significantly different from those obtained from either the meta or the para isomer. However, with the ortho isomer the spots with $R_{F}$ values $0.05,0.14$, 0.37 and 0.46 (spots $a, b, d$ and $e$ ) were not due to single substances. Hydrolysis of each of these spots with sodium hydroxide gave rise to two phenolic products that could be distinguished by chromatography, one of which readily reduced ammoniacal silver nitrate. These metabolites were not further investigated and were presumed to arise from hydroxylation of the aromatic ring.

\section{Enzymic hydrolysis of carbamates}

The radioactively labelled carbamate insecticides were incubated at $\mathrm{pH} 7.4$ in $0.1 \mathrm{M}$-phosphate buffer with fly abdomen enzymes at $30^{\circ} \mathrm{C}$ or at $37^{\circ} \mathrm{C}$ with the $10000 \mathrm{~g}$ supernatant of $1 \mathrm{~g}$ of mouse liver and with the cofactors listed in Table 4. Reaction mixtures were extracted after $0.5 \mathrm{~h}$ and the ether extracts chromatographed on Whatman no. SG81 paper as described above. Zones corresponding to $m$-tert.-butylphenol, $o$-isopropoxyphenol and 3,5di-tert.-butylphenol were located by comparison with reference samples and the appropriate zones were cut out and assayed for radioactivity. Conversion into the phenol was expressed as a percentage of the total radioactivity used (Table 4).

Similar experiments with mouse liver microsomal fraction from $1 \mathrm{~g}$ liver $(100000 \mathrm{~g}$ sediment) showed 


\section{Table 4. Cofactor-dependent cleavage of some N-methylcarbamates}

Incubation mixtures were prepared as in Table 3 except that cofactors and glucose 6-phosphate were added as shown below. Substrates were: A, m-tert.-butylphenyl $N$-methylcarbamate; B, $o$-isopropoxyphenyl $N$ methylcarbamate; C, 3,5-di-tert.-butylphenyl $N$-methylcarbamate.

$\%$ of substrate cleaved

\begin{tabular}{|c|c|c|c|c|c|c|c|c|c|}
\hline \multirow{2}{*}{$\begin{array}{rr}\text { Source of enzyme } & \ldots \\
\text { Substrate } & \ldots \\
\text { Cofactors } & \end{array}$} & \multicolumn{3}{|c|}{ Mouse liver } & \multicolumn{3}{|c|}{ Housefly } & \multicolumn{3}{|c|}{ Blowfly } \\
\hline & . $^{\mathbf{A}}$ & B & C & A & B & C & $\mathbf{A}$ & B & $\mathrm{C}$ \\
\hline None & 0.02 & 0.03 & 0.01 & 0.01 & 0.02 & $\mathbf{0}$ & $\mathbf{0}$ & 0.02 & 0 \\
\hline NAD ${ }^{+}$, glucose 6-phosphate & 0.43 & - & - & 0.11 & - & - & 0.16 & - & - \\
\hline NADP $^{+}$, glucose 6-phosphate & 1.13 & - & - & 0.28 & - & - & 0.22 & - & - \\
\hline $\begin{array}{l}\text { NAD }^{+}, \text {NADP }^{+} \text {, glucose } 6- \\
\text { phosphate }\end{array}$ & 1.41 & 2.11 & 1.61 & 0.34 & 0.43 & 0.27 & 0.31 & 0.37 & 0.23 \\
\hline
\end{tabular}

that no hydrolysis occurred in unfortified preparations and that addition of either NADPH or a mixture of $\mathrm{NADP}^{+}$, glucose 6-phosphate and glucose 6-phosphate dehydrogenase to the incubation mixture resulted in the liberation of phenol equivalent to $2 \%$ of the substrate added.

No hydrolysis of the three carbamates used was detectable when they were incubated with a $1: 10$ dilution of mouse blood at $37^{\circ} \mathrm{C}$ for $30 \mathrm{~min}$ at $\mathrm{pH}$ 7.4.

\section{Metabolism of m-tert.-butylphenyl N-methylcarba- mate in vivo}

Groups of insects weighing in all about $1-2 \mathrm{~g}$ were dosed topically with $\left[{ }^{3} \mathrm{H}\right] m$-tert.-butylphenyl $N$ methylcarbamate and extracted after either $12 \mathrm{~h}$ or $24 \mathrm{~h}$ by grinding with sand and ether as described above. Unextracted material was enzymically hydrolysed and the solution re-extracted. The pooled extracts were chromatographed in solvent system $A$ (Table 1) and eight spots were detected at the same $R_{F}$ values and having the same colour reactions as those found in the enzyme incubation experiments. The quantitative values obtained in these experiments with $\left[{ }^{3} \mathrm{H}\right] m$-tert. -butylphenyl $N$ methylcarbamate are summarized in Table 5; the difference between the total extractable metabolite and that extractable only before enzymic treatment has been assumed to be conjugated material. Qualitative experiments were also made with larvae of the porina moth (Wiseana sp.) and the whitefringed weevil (Graphognathus leukoloma): chromatography of these extracts also showed eight spots, which were shown by the chromatography, ionophoresis and colour reactions described above to be the same as those formed by mice.

Mice (25 g) were starved for $24 \mathrm{~h}$ and dosed orally or intraperitoneally with $1 \mathrm{mg}$ of $\left[{ }^{3} \mathrm{H}\right] m$-tert.butylphenyl $N$-methylcarbamate in $0.25 \mathrm{ml}$ of aq. $0.5 \%$ Triton $X-100$ solution. No significant differences in excretion rates were discerned after the two methods of administration, and in six experiments $70 \%$ (59-82\%) of the radioactivity was excreted in the urine after $24 \mathrm{~h}$. A further $7.9 \%$ (5-12\%) was excreted during the next 3 days.

Each $24 \mathrm{~h}$ collection of urine was extracted as described above, before and after treatment with the hydrolytic enzyme. In contrast with the insect experiments, material containing $8.6 \%$ (3.6-17.9\%) of the radioactivity in mouse urine was not hydrolysed by the enzymic treatment and this fraction was not further investigated. Extracted metabolites were chromatographed on Whatman no. SG81 paper as described above, and eight spots were recognized with $R_{F}$ values and colour reactions identical with those of the metabolites $a-h$ found in the insect and enzymic experiments. Hydrolysis of each of the metabolites with $1 \mathrm{M}$-sodium hydroxide yielded phenolic materials identical in chromatographic and ionophoretic properties and colour reactions with $m$-tert.-butylphenol or $m$ - $(\beta$-hydroxytert.-butyl)phenol, as shown in the experiments with enzymic metabolism described above.

\section{DISCUSSION}

The same seven metabolites of $m$-tert.-butylphenyl $N$-methylcarbamate were found in all the species and instars examined, though the amounts of each metabolite showed some species variation (Table 5). The most striking quantitative difference was in the amount found of the hydrolysed metabolites, $m$-tert.-butylphenol and $m$-( $\beta$-hydroxy-tert.-butyl)phenol, which in unconjugated or conjugated forms accounted for most of the metabolized dose in mice and meal worms. Esterases that can hydrolyse carbamate insecticides to the corresponding phenols have been found in insect haemolymph and in vertebrate blood (Casida, 1963; Matsumura \& Sakai, 1968), but it seems likely that these were of only minor significance in the formation of the two phenolic metabolites. The lack of any hydrolysis of this insecticide in fly homogenates has been 


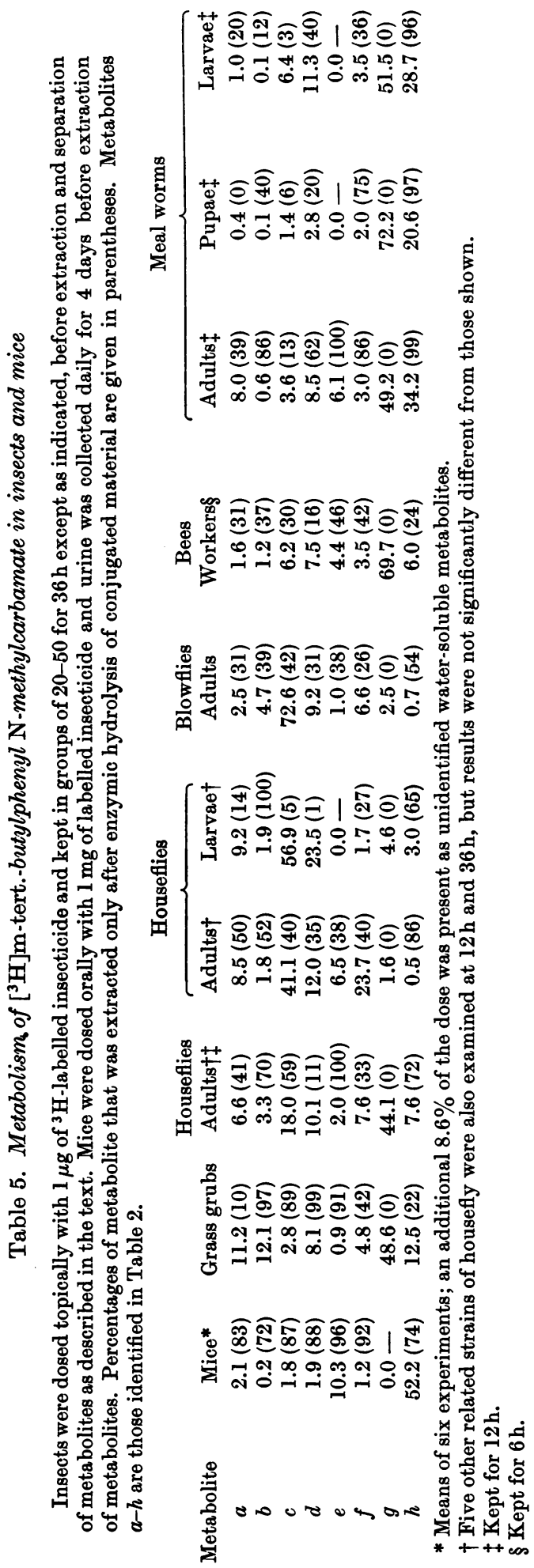

observed by Moorefield (1960). The action of gut esterases in the mice seems also to be unlikely, since little difference in the pattern of excreted metabolites was found after either oral or intraperitoneal administration of the insecticide. The unfortified liver microsomal fraction, the liver $100000 \mathrm{~g}$ supernatant and mouse blood contained an abundance of esterase capable of rapid hydrolysis of, for instance, phenyl butyrate or ethyl acetate, but these had no significant action on the insecticide (J. N. Smith \& J. C. Turner, unpublished work). Hydrolysis of $m$-tert.-butylphenyl $N$-methylcarbamate by fly homogenate was also negligible until $\mathrm{NADP}^{+}$and glucose 6-phosphate were added (Table 4). Similarly the mouse liver $10000 \mathrm{~g}$ supernatant gave no hydrolysis until these cofactors were added.

It seems probable that most of the cleavage of the carbamate insecticide in vivo was brought about by a microsomal NADPH-dependent system similar to that observed by Neale (1967) and by Nagatsugawa \& Dahm (1969), which liberates $p$-nitrophenol from parathion (OO-diethyl $O$ - $p$-nitrophenyl phosphorothionate) only in the presence of the usual hydroxylation cofactors found in the microsomal fraction. If this is so, then all the detoxication reactions undergone by this insecticide are catalysed by the microsomal system, though the species differences between the degree of hydroxylations and the extent of ester-cleavage suggest that these two processes are not mediated by the same enzyme.

No metabolites formed by hydroxylation of the aromatic ring were found in any of the species examined, and those oxidized metabolites present may be divided into two groups. They are metabolites resulting from hydroxylation of the tert.butyl group and those formed as a consequence of hydroxylation in the $N$-methylcarbamoyl function. It seems reasonable to include $m$-tert.-butylphenyl carbamate (metabolite $f$ ) as well as metabolite $b$ (Table 2) in this group since they may be assumed to be the products of oxidative demethylation.

Metabolites were present where both types of oxidation had taken place (metabolites $a$ and $b$ ), though these usually represented less than $10 \%$ of the total oxidized metabolites. On the other hand, the grass grub, which has the lowest rate of oxidation by the microsomal fraction of any insect examined in this laboratory (Hook, Jordan \& Smith, 1968), converted about half of the insecticide into doubly oxidized metabolites (Table 5). Formation of the doubly oxidized products was not dependent on the prior formation of large quantities of the singly oxidized metabolites, since in both mouse (Fig. 1) and fly enzyme systems the rate of formation of the doubly hydroxylated products was constant from the start of the incubation.

The analytical results from experiments with intact insects and mice suggest that the mechanisms 
that give rise to the two types of oxidized metabolites may be different. Thus in blowflies the amount of hydroxylation of the tert.-butyl group greatly exceeds that of the $N$-methylcarbamoyl function (Table 5). If metabolites $c$ and $e$ are taken as an index of the alkyl hydroxylation and metabolites $d$ and $f$ (Table 2) as an index of the oxidative demethylation pathway the ratio of these is about $5: 1$ in blowflies and 4:1 in mice compared with a ratio of $1: 3$ in the grass grub.

This distribution of metabolites in the intact animal does not, however, reflect in the rates of hydroxylation by the microsomal fraction in the enzymic experiments with flies and mouse liver (Table 4). In these experiments the oxidative demethylation process takes place at a greater rate than the oxidation of the tert.-butyl group. This does not exclude the possibility that more than one microsomal hydroxylase is concerned in the detoxication of this insecticide, since the enzyme systems were provided in vitro with optimum concentrations of cofactors and in these circumstances hydroxylation rates (as $\mu \mathrm{mol} / \mathrm{min}$ per fly) may be much greater than in intact insects (Jordan \& Smith, 1970). If more than one hydroxylation system is present in the microsomal fraction of mouse liver or in insects the relative effectiveness of these systems would be modified by the availability of cofactors and differences in the affinities of several possible systems for them. It is not thought that limited availability of substrate in the experiments described above could have affected either the results obtained in vivo or those obtained in vitro, since the doses and concentrations used were sufficient to give maximum and constant rates of metabolism (Hook \& Smith, 1967; Jordan \& Smith, 1970).

It has been shown with other carbamate insecticides that the hydroxylated metabolites may still possess significant anti-cholinesterase activity and that some metabolites may exceed the effectiveness of the parent insecticide in their ability to inhibit this enzyme (Oonithan \& Casida, 1968; Dorough, 1970). It is unlikely, however, that oxidation processes in the whole insect give any effective activation of a carbamate insecticide, since the oxidation products are themselves substrates for those enzymes that detoxify by conjugation. In the present work major proportions of all the metabolites were present in a form that was not extractable by ether until after enzymic hydrolysis (Table 5). It seems probable that the critical detoxication process that inactivates the insecticide is the oxidation or NADPH-dependent ester-cleavage in the microsomal fraction and the toxicity of this insecticide is inversely related to the ability of the various species to carry out oxidation in the microsomal fraction. The toxicity is thus low in flies (approx. $50 \mathrm{mg} / \mathrm{g}$ ), which are among the most active insects so far as oxidations by the microsomal fraction are concerned (Hook et al. 1968), and high in those species, like grass grubs and bees (Metcalf \& Fukuto, 1965), the microsomal fraction of which is known to have only a low oxidation ability.

This work has been supported by equipment grants from the New Zealand University Grants Committee, the Department of Scientific and Industrial Research, the Golden Kiwi Board of Control and the Internal Research Committee of this University. P.G.C.D. was maintained in part by a grant from Merck, Sharpe and Dohme Ltd.

\section{REFERENCES}

Casida, J. E. (1963). A. Rev. Ent. 8, 39.

Casida, J. E. (1969). In Microsomes and Drug Oxidations, p. 517. Ed. by Gillette, J. R. \& Fouts, J. R. New York: Academic Press Inc.

Casida, J. E. (1970). J. agric. Fd Chem. 18, 753.

Dorough, H. W. (1970). J. agric. Fd Chem. 18, 1015.

Feigl, F. (1956). Spot Tests in Organic Analysis. New York: Elsevier Publishing Co.

Fraser, J., Greenwood, D., Harrison, I. R. \& Wells, W. H. (1967). J. Sci. Fd Agric. 18, 372.

Gemrich, E. G. (1967). J. agric. Fd Chem. 15, 617.

Hilton, B. D. \& O'Brien, R. D. (1964). J.agric. Fd Chem. $12,236$.

Hook, G. E. R., Jordan, T. W. \& Smith, J. N. (1968). In Enzymatic Oxidations of Toxicants, p. 27. Ed. by Hodgson, E. Raleigh : North Carolina State University Press.

Hook, G. E. R. \& Smith, J. N. (1967). Biochem.J.102, 504.

Jordan, T. W., McNaught, R. W. \& Smith, J. N. (1970). Biochem. J. 118, 1.

Jordan, T. W. \& Smith, J. N. (1970). Int. J. Biochem. 1, 139.

Kolbezen, M. J., Metcalf, R. L. \& Fukuto, T. R. (1954). J.agric. Fd Chem. 2, 864.

Kolloff, R. H., Breuklander, L. J. \& Barkley, L. B. (1963). Analyt. Chem. 35, 1651.

Matsumura, F. \& Sakai, K. (1968). J.econ. Ent.61, 598.

Metcalf, R. L. \& Fukuto, T. R. (1965). J. agric. Fd Chem. 13, 220.

Metcalf, R. L., Fukuto, T. R., Collins, C., Borck, K., Abdel Aziz, S., Munoz, R. \& Cassil, C. C. (1968). J. agric. Fd Chem. 16, 300.

Metcalf, R. L., Fukuto, T. R., Wilkinson, C., Fahmy, M. H., El Aziz, S. A. \& Metcalf, E. R. (1966). J. agric. $F d$ Chem. 14, 555 .

Metcalf, R. L., Fukuto, T. R. \& Winton, M. Y. (1962). J. econ. Ent. 55, 345.

Moorefield, H. H. (1960). Ent. Soc. Am. Misc. Publ. no. 2, p. 145.

Nagatsugawa, T. \& Dahm, P. A. (1969). Biochem. Pharmac. 18, 1103.

Neale, R. A. (1967). Biochem. J. 105, 289.

Oonithan, E. S. \& Casida, J. E. (1968). J.agric. Fd Chem. 16, 28.

Raiford, W. C. \& Inman, G. O. (1934). J. Am. chem. Soc. 56,1586 .

Turner, J. C. (1968). Int.J. appl. Radiat. Isotopes, $20,499$.

Winteringham, F. P. W. (1969). A. Rev. Ent. 14, 409. 